\title{
Correction: Improving the $\mathrm{pH}$-stability of Versatile Peroxidase by Comparative Structural Analysis with a Naturally-Stable Manganese Peroxidase
}

\section{The PLOS ONE Staff}

There are errors in the Funding section. The complete, correct funding information is as follows:

This work was funded by the Commission of the European Communities through the PEROXICATS (KBBE-2010-4-265397, Novel and more robust fungal peroxidases as industrial biocatalysts) and INDOX (KBBE-2013-7-613549, "Optimized oxidoreductases for medium and large scale industrial biotransformations") projects to ATM, by the Spanish Ministerio de Economía y Competitividad (MINECO) through the HIPOP (BIO2011-26694, "Screening and engineering of new high-redox potential peroxidases") to FJR-D, NOESIS (BIO-2014-56388-R, "New oxidative enzymes for sustainable industries") to FJR-D, BFU2011-24615 and CSD200900088 projects, and by the EC 7th Framework Programme (FP7/2007-2013) under BioStructx5959 (grant agreement $\mathrm{N}^{\circ} 283570$ ). VS-J and FJR-D thank the financial support of a research fellowship (Formación de Personal Investigador, FPI) and a Ramón y Cajal contract of the Spanish MINECO, respectively. The funders had no role in study design, data collection and analysis, decision to publish, or preparation of the manuscript.

The publisher apologizes for the errors.

\section{Reference}

1. Sáez-Jiménez V, Fernández-Fueyo E, Medrano FJ, Romero A, Martínez AT, Ruiz-Dueñas FJ (2015) Improving the $\mathrm{pH}$-stability of Versatile Peroxidase by Comparative Structural Analysis with a NaturallyStable Manganese Peroxidase. PLoS ONE 10(10): e0140984. doi:10.1371/journal.pone.0140984 PMID: 26496708

\section{G open access}

Citation: The PLOS ONE Staff (2015) Correction: Improving the $\mathrm{pH}$-stability of Versatile Peroxidase by Comparative Structural Analysis with a NaturallyStable Manganese Peroxidase. PLoS ONE 10(11): e0143267. doi:10.1371/journal.pone.0143267

Published: November 12, 2015

Copyright: $\odot 2015$ The PLOS ONE Staff. This is an open access article distributed under the terms of the Creative Commons Attribution License, which permits unrestricted use, distribution, and reproduction in any medium, provided the original author and source are credited. 